\title{
ANÁLISE TECTÔNICA DE TERRENOS: METODOLOGIA, APLICAÇÃO EM CINTURÕES OROGÊNICOS E EXEMPLO DAS PROVÍNCIAS TOCANTINS E BORBOREMA, BRASIL.
}

\author{
Lauro Cézar Montefalco de Lira Santos ${ }^{1,2}$, Reinhardt A. Fuck ${ }^{1}$, \\ Edilton José dos Santos ${ }^{3}$, Elton Luiz Dantas ${ }^{1}$
}
1 - Universidade de Brasilia. Laboratório de Geocronologia, Campus Universitário Darcy Ribeiro. CEP: 70910900, Asa Norte, Brasília, DF, Brasil. Caixa Postal: 04405.lauromontefalco@gmail.com, reinhardt@unb.br, elton@unb.br
2 - Universidade Federal de Campina Grande. Unidade Acadêmica de Mineração e Geologia, UFCG. CEP: 58109.970, Av. Aprígio Veloso 882, Bodocongó, Campina Grande-PB, Brasil.
3 - CPRM - Serviço geológico do Brasil.SUREG Recife. CEP: 50770-011, Avenida Sul, Afogados 2291, Recife-PE, Brasil. edilton.santos@cprm.gov.br

Recebido em 30 de outubro de 2014; aceito em 23 de março de 2015

\begin{abstract}
Resumo: Em regiões afetadas por tectônica convergente é comum a presença de um ou mais elementos alóctones que supostamente foram acrescidos à margem continental. Se esses elementos forem limitados por falhas ou zonas de cisalhamento importantes, são chamados de terrenos. Os terrenos apresentam tamanhos variáveis e, por vezes, representam fragmentos crustais alóctones, que podem apresentar histórias evolutivas individuais anteriores à sua acreção. Terrenos podem ser classificados em função de suas características individuais (estratigráficos, fragmentados ou metamórficos) e pelo tipo de acreção a que foram submetidos (frontal, lateral ou oblíqua). A análise de terrenos representa técnica multidisciplinar utilizada no estudo de cinturões orogênicos que tem como objetivo principal o entendimento dos diversos processos geodinâmicos relacionados a ambientes de subducção e complexos colisionais, sendo amplamente aplicada em diversas regiões do planeta. Em alguns orógenos pré-cambrianos brasileiros tem-se reconhecido padrões que permitem interpretar sua evolução como resultado de processos acrecionários e de colagem de terrenos, descritos em vários segmentos das províncias Tocantins e Borborema.
\end{abstract}

Palavras-Chave: Cinturões orogênicos, tectônica acrescionária, terrenos alóctones.

Abstract: TECTONIC ANALYSIS OF TERRANES: METHODOLOGY, APPLICATION IN OROGENIC BELTS AND EXAMPLES FROM TOCANTINS AND BORBOREMA PROVINCES, BRAZIL. In regions affected by convergent tectonics, the presence of some allochtonous elements that were accreted to the continental margin is common. If these elements are bounded by important faults or shear zones, they are called terranes. Terranes present variable sizes and may represent allochtonous crustal fragments, with individual evolutive history previous to their accretion to the continental margin. Terranes can be classified as a function of its individual characteristics (stratigraphic, disrupted or metamorphic) and formed by frontal, lateral or oblique accretion. Terrane analysis represents a multidisciplinary technique used in studying orogenic belts that aims the understanding of several processes related to subduction and collisional complexes. Certain patterns recognized in some Brazilian Precambrian orogens allow to interpret their evolution as the result of accretion tectonic events recorded in the Tocantins and Borborema provinces.

Key-words: Orogenic belts, Accretion Tectonics, Allochtonous Terranes.

\section{INTRODUÇÃO}

Cinturões orogênicos constituem províncias estruturais complexas, que podem ter sido submetidas a diversos episódios tectônicos, magmáticos e metamórficos. Frequentemente, esses processos dificultam estudos genéticos e correlações estratigráficas, além de obliterar estruturações anteriores, comprometendo a análise evolutiva. Modelos pioneiros de tectônica de placas em cinturões orogênicos enfatizavam principalmente seções ortogonais à direção regional do orógeno, não levando em consideração a possibilidade de importantes deslocamentos longitudinais ou oblíquos. Estes modelos, entretanto, não satisfaziam o entendimento de cinturões orogênicos complexos como, por exemplo, a Cordilheira Norte Americana.

Boa parte dos orógenos conhecidos apresenta ao menos uma região cujos elementos estratigráficos devem ser considerados potencialmente alóctones, com respeito às correlações paleogeográficas seja com relação aos seus próprios elementos ou à margem continental (Howell, 1995). Este trabalho apresenta os principais elementos envolvidos na análise tectônica de terrenos, demonstrando sua importância, com aplicação dos conceitos nas províncias Tocantins e Borborema.

\section{HISTÓRICO DO MODELO E CONCEITUAÇÃO}

Tendo em vista as complicações envolvidas nas correlações estratigráficas, estruturais e paleontológicas observadas nos orógenos ditos cordilheiranos, o modelo de tectônica acrescionária e de terrenos vem sendo utilizado ao redor do mundo para explicar as diversas relações de aloctonia. O modelo teve sua origem na região das montanhas Klamath, norte da Califórnia, Estados Unidos da América. A geologia da região foi pioneiramente dividida por Irwin (1960) em uma série de cinturões com evolução estrutural e estratigráfica distinta. Cada cinturão foi dividido em sub-cinturões, chamados posteriormente de terrenos (Irwin, 1972). Na mesma época, autores como Monger e Ross (1971) sugeriam que alguns 
terrenos poderiam ser alóctones, como alguns blocos crustais exóticos da Cordilheira em relação ao continente norte-americano.

$\mathrm{Na}$ década de 1970 diversos trabalhos enfatizaram a importância de zonas de cisalhamento ou falhas paralelas como elementos estruturais importantes na evolução de cinturões orogênicos. Esses estudos eram associados a dados paleontológicos e paleomagnéticos, com o objetivo de obter informações quantitativas ou qualitativas sobre grandes deslocamentos paralelos ou subparalelos à margem continental (Irving e Yole, 1972; Packer e Stone, 1972). Ao final da década de 1970, Jones et al. (1977), pioneiramente propuseram uma trajetória de deslocamento específica para o bloco crustal Wrangellia. De acordo com as interpretações desses autores, Wrangellia teria se originado no Oceano Pacífico e se deslocado para leste até ser acrescido à Placa NorteAmericana, sendo considerado um caso clássico de terreno de afinidade exótica ou far-travelled. O Terreno Wrangellia teria ainda sido deslocado por falhamentos transcorrentes na própria margem continental por processos pós-acrecionários de dispersão.

$\mathrm{Na}$ década seguinte o conceito de terrenos foi consolidado pelos trabalhos clássicos de Coney et al. (1980) e Jones et al. (1983), sendo discretamente modificado por Howell $(1989,1995)$. De acordo com estes autores, um terreno tectonoestratigráfico corresponderia a um pacote de rochas limitado por falhas ou zonas de cisalhamento importantes (possíveis suturas) com estratigrafia, ambiente e história geológica distintas dos terrenos adjacentes.

A aplicação direta do modelo tem sido utilizada em faixas móveis de diversas idades, cobrindo todo o Fanerozoico e a maior parte do Pré-Cambriano, tais como a própria Cordilheira Norte-Americana (Coney et al. 1980; Colpron et al. 2007), toda a região do Circum-Pacífico (Schermer et al. 1984; Mortimer, 2004), Apalaches (Williams e Hatcher 1982), terrenos pré-cordilheiranos na Argentina (Ramos et al. 1998), Província Grenville (Mallard e Rogers, 1997), Namaqua-Natal (Egllington, 2006) e Yavapai-Mazatzal (Magnani et al. 2004), os escudos Tuareg (Black, 1994) e Arábico-Nubiano (Stoeser and Frost, 2006; Cox et al., 2012), além de crátons arqueanos, como Yilgarn na Austrália e Slave no Canadá (Zegers e van Keken, 2001). No Brasil, estudos modernos têm proposto que as províncias Borborema, Mantiqueira, Rondônia-San Ignacio e Sunsás foram edificadas por mecanismos de colagem e acreção de terrenos (Santos 1996; Hackspacher et al., 1997; Brito Neves et al. 2000; Scandolara et al., 2001; Rizzotto e Quadros, 2005; Basei et al. 2008; Heilbron et al. 2008; Faleiros et al. 2011).
De acordo com a classificação apresentada por Howell (1995), terrenos tectonoestratigráficos podem ser agrupados em três categorias, em função de sua organização interna:

\section{$\underline{\text { Terrenos estratigráficos }}$}

Caracterizados por sequências de estratos, cujas relações deposicionais podem ser demonstradas. Podem representar fragmentos de continentes, fragmentos de margens continentais, fragmentos de arcos magmáticos e fragmentos de bacias oceânicas. Ex: Terreno Torlesse, Nova Zelândia.

\section{Terrenos metamórficos}

Terrenos nos quais a recristalização metamórfica penetrativa obliterou completamente a estratigrafia original. Ex: Terreno Tamana, Alasca.

\section{Terrenos fragmentados}

Caracterizados pela presença de blocos de rochas com idades heterogêneas. Podem conter fragmentos de ofiolitos, calcários marinhos, grauvacas, etc. Ex. Central Belt Terrane, Califórnia.

\subsection{Conceitos complementares}

Alguns termos específicos surgiram para abranger as diversas descrições de cinturões orogênicos que experimentaram tectônica de terrenos. Os termos são apresentados a seguir segundo as definições compiladas de Schermer et al., (1984), Howell (1995) e Brito Neves (2011).

i. Terrenos exóticos - Áreas circundadas por suturas e caracterizadas por contingente petrográfico, estratigráfico, paleontológico e/ou paleolatitudes distintas dos terrenos vizinhos.

ii. Terrenos compostos - Conjunto formado por uma série de terrenos individualizáveis que foram amalgamados em algum momento de suas trajetórias.

iii. Terrenos disjuntos - Terrenos que são espacialmente correlacionáveis, mas correspondem a fragmentos espacialmente distintos.

iv. Eventos externos e internos - Eventos que ocorreram em algum momento que antecede a acreção à margem continental (externos) ou posteriores à acreção (internos).

v. Docagem - Em regimes de subducção, na região da fossa, aportam fragmentos de crosta continental, frações de arcos de ilhas, platôs submarinos. Estes fragmentos tendem a colidir como terrenos.

vi. Limite de Terrenos - Comumente são definidos como zonas de sutura ou falhas/zonas de cisalhamento de grande expressão. 


\section{MECANISMOS DE COLAGEM E FRAGMENTAÇÃO DE TERRENOS}

Vários mecanismos foram propostos para explicar processos de formação e trajetória de terrenos. O resultado mais imediato na acreção de terrenos é sempre (ou quase) o crescimento crustal, mas eventos de retrabalhamento e reciclagem crustal também podem estar associados. Crescimento crustal é o resultado da adição progressiva de material às margens continentais. Um caso clássico é a Cordilheira Norte-americana, onde os diversos terrenos adicionaram material à margem oeste de Laurentia no fim do Paleozoico (Coney et al., 1980).

Durante a evolução de terrenos, dois processos fundamentais estão envolvidos (Schermer et al. 1984): i) Construção e ii) Destruição e modificação continental.

\subsection{Construção (Amalgamação e Acreção)}

Amalgamação de terrenos ocorre quando dois terrenos colidem anteriormente a um episódio acrescionário. Acreção refere-se à adição de terrenos a uma margem continental, culminando em processo de docagem. Acreção é um processo muito importante, pois pode afetar consideravelmente a história evolutiva do terreno, obscurecendo ou obliterando feições anteriores.

Durante eventos acrecionários, zonas de cisalhamento inversas representam os elementos estruturais mais importantes, principalmente em processos de colagem frontal de terrenos à margem continental (Figura 1). Zonas de cisalhamento de alto ângulo, no entanto, também representam importantes elementos estruturais, em consequência de acreção oblíqua ou colagem lateral, ou ainda em virtude de reativação de falhas contracionais antigas.

Ao longo destes processos, é comum a formação de mélanges e rochas metamórficas de alta pressão (xistos azuis ou eclogitos), como no caso dos terrenos Yolla Bolly e Picket Peak do Complexo Franciscano (oeste dos Estados Unidos da América), que são terrenos metamórficos submetidos a condições de fácies xisto azul, associados a eventos de acreção (Jayko e Blake, 1989; Bolhar e Ring, 2001). Por outro lado, é comum metamorfismo de alta temperatura, com formação de fundidos anatéticos como, por exemplo, a atividade magmática e metamórfica produzida pela intrusão do Coast Plutonic Complex na Columbia Britânica (região oeste do Canadá) (Monger et al. 1982). Outro aspecto importante na indicação de acreção de terrenos é a presença de ofiolitos, vinculados a regimes de obducção sin-acrescionária e preservados em casos de baixas taxas de exumação do orógeno.
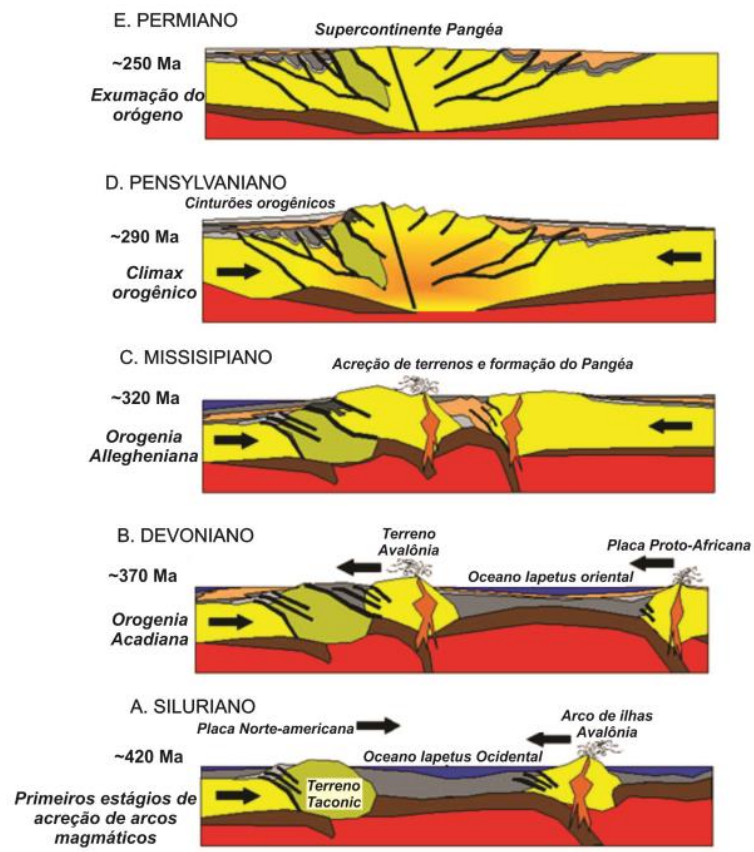

Figura 1. Diagrama tectônico demonstrando acreção de dois terrenos por meio de colagem frontal (Tacônico e Avalônia) nos Apalaches da Nova Inglaterra. Retirado de

http://3dparks.wr.usgs.gov/nyc/valleyandridge/valleyandridge.ht $m$.

\subsection{Destruição ou modificação continental (Rifteamento e Dispersão)}

De maneira oposta à construção continental, eventos de destruição e modificação continental obliteram limites de terrenos. De acordo com Howell (1995) e Schermer et al. (1984), dispersão é o processo no qual terrenos previamente amalgamados são divididos em fragmentos menores e espalhados ao longo da margem continental.

O processo pode ocorrer por meio de rifteamento ou por falhas de movimentação direcional (Figura 2), inclusive durante eventos de acreção ou colagem, como no caso de subducção oblíqua. Exemplo desse tipo de processo é a falha de San Andreas na costa oeste dos Estados Unidos da América, que apresenta forte componente dispersivo, bem como os sistemas de falhas de Fairweather, Denali e Tintina, no contexto da Cordilheira Norte-Americana. Dispersão de terrenos é descrita ao longo de quase toda margem do Pacífico, tanto relacionados a subducção oblíqua ou essencialmente a deslocamentos transcorrentes.

Processos de dispersão devem ser estudados em detalhe e com cautela, pois são responsáveis pela formação de terrenos disjuntos. Estes terrenos podem ser estratigraficamente correlacionados, porém não apresentam boa correlação espacial. 0 melhor exemplo é o terreno Wrangellia mencionado 
anteriormente. Este terreno ocorre seccionado por lineamentos de extensão regional. Dados paleomagnéticos indicam que estas fatias crustais eram significativamente menores (Hillhouse et al. 1982).

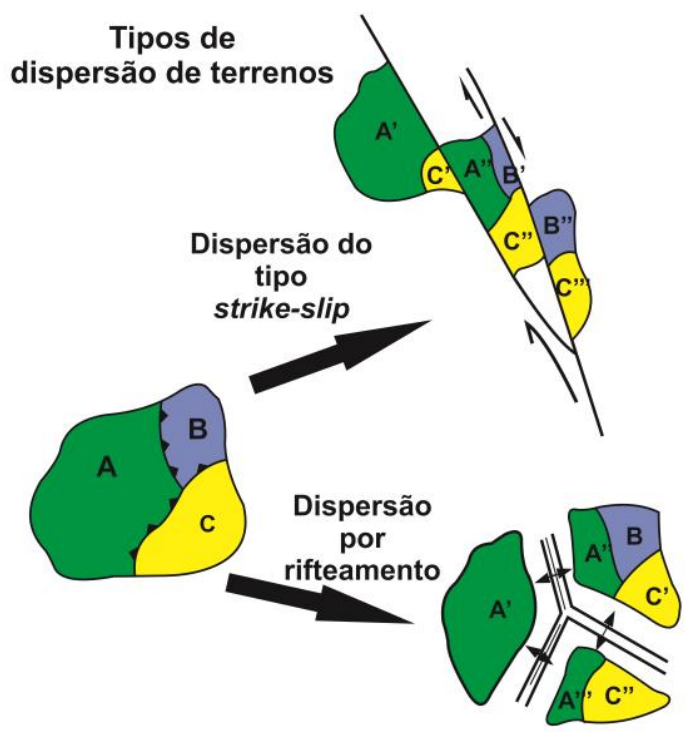

Figura 2. Representação dos dois principais processos de dispersão de terrenos modificado de Howell 1995.

\section{PLATÔS OCEÂNICOS E TERRENOS}

Aproximadamente $10 \%$ da crosta oceânica atual são formados por segmentos espessos caracterizados por altos batimétricos e margens íngremes. Essas regiões são chamadas de platôs oceânicos e são interpretados como restos de fragmentos de continentes, traços de hot-spots, arcos remanescentes ou diversos tipos de pilhas vulcânicas (Nur e Ben-Avraham, 1981; Schubert e Sandwell, 1989; Vogt e Geria, 2012).

A natureza original de platôs oceânicos é conhecida por meio de dados de sondagem ou dragagens do assoalho oceânico. Alguns platôs representam fragmentos continentais, tais como o Platô de Campbell (Grobys et al. 2009) próximo à Nova Zelândia e Kerguelen no Oceano Índico (Frey et al. 2000), enquanto outros foram originados a partir de ilhas oceânicas ou restos de arcos magmáticos remanescentes, como a elevação de Galápagos e o platô Kyushi Palau, localizado próximo às Filipinas (Schermer et al., 1984).

Independente de sua origem, platôs são considerados precursores de terrenos, tendo como destino final a docagem a uma margem continental por meio de processos de acreção e colisão, independente de eventos de amálgama pré-acreção (Schubert e Sandwell, 1989). Entretanto, platôs oceânicos não são exatamente terrenos tectonoestratigráficos, pois não representam fragmentos crustais limitados por falhas, embora seja reconhecido que ao encontrar uma margem continental ativa, a tendência geral seja de se tornar um terreno alóctone, sendo, por fim, soldado à margem continental. Esta interpretação é baseada no fato de que muitos terrenos possuem similaridades geoquímicas e geocronológicas com platôs oceânicos, sugerindo se tratarem de paleoplatôs. Exemplos de platôs oceânicos que foram acrescidos a zonas de subducção fósseis e modernas correspondem aos Platôs de Okhotsk, Shirhove Ridge e Carnegie Ridge (Schermer et al., 1984), no contexto circum-pacífico. Os terrenos Wrangellia e Cache Creek na cordilheira norte-americana são exemplos de terrenos alóctones que correspondem a paleo-platôs.

\section{CARACTERÍSTICAS DE TERRENOS}

\subsection{Limites}

Como exposto em seu conceito original, todo terreno deve ser separado dos terrenos adjacentes por falhas ou zonas de cisalhamento. As estruturas em limites de terrenos podem estar associadas a conjuntos petrotectônicos variados, tais como cinturões alinhados formados por mélanges, corredores regionais miloníticos a ultramiloníticos, duplexes compressivos e tectônica de nappes. A associação com rochas metamórficas específicas como xistos azuis ou a eclogitos do tipo C (Coleman et al. 1965) é um indicativo de processos acrescionários.

Por outro lado, em muitos limites as zonas de falha ou cisalhamento não possuem expressão regional em imagens de satélites, mapas geofísicos ou em fotografias aéreas. Em geral, este é o caso de vários terrenos pré-cambrianos, sendo tais limites ditos ocultos (cryptic), imperceptíveis. É comum ainda que muitos limites possam ter seu registro apagado por eventos deformacionais posteriores.

Schermer et al. (1984) e Howell (1995) advogam que limites entre terrenos podem ser muitas vezes inferidos por meio de comparação de áreas com unidades estratigráficas contrastantes e não necessariamente correspondem a suturas.

\subsection{Tamanho}

Terrenos podem variar consideravelmente de tamanho, desde dimensões continentais a áreas de poucos quilômetros quadrados. Fragmentos continentais espessos, arcos de ilhas, flakes e fatias tectônicas podem ser considerados terrenos, desde que se adequem aos critérios conceituais. Por outro lado, a escala de análise é de fundamental importância para determinar quantos e quais fragmentos devem ser considerados terrenos. 


\subsection{Deslocamentos e Trajetórias}

Os deslocamentos que um terreno pode sofrer também são variáveis, podendo apresentar deslocamentos em escala continental, ou não maiores do que alguns quilômetros. Medidas de deslocamento de terrenos podem ser feitas de várias formas, desde técnicas geológicas convencionais (análise estrutural, estudos estratigráficos, evidências de aparecimento ou desaparecimento de paleofauna) ou até métodos sofisticados como Paleomagmetismo. Esta última corresponde a uma técnica bastante robusta, pois determina deslocamentos latitudinais em escalas regionais ou até globais, podendo definir trajetórias dos diversos terrenos como mostram Schermer et al. (1984).

\subsection{Evidências de Formação de Terrenos}

Algumas feições estruturais e estratigráficas podem registrar o timing de episódios de amálgama e de acreção, adicionando valiosa informação à análise de terrenos (Figuras 3 e 4). Howell (1995) define algumas feições fundamentais:

i. Sequência de Sobreposição (Overlap Sequence) Quando dois ou mais terrenos são amalgamados, existe a possibilidade de uma bacia sedimentar se desenvolver sobre a zona de sutura; neste caso uma camada sedimentar pode recobrir ambos os terrenos, representando, assim, o tempo mínimo (timing) pós-colagem. Um bom exemplo é a Formação Chuckanut (Paleoceno) depositada sobre os terrenos ocidentais da região da Colúmbia Britânica. A formação apresenta registro paleontológico rico. A idade de deposição, particularmente de sua seção basal, determina a idade mínima da colagem (Howell, 1989, 1993; Mustoe e Gannaway, 1997).

ii. Suturamento Plutônico (Stitching Plutons) Acreção de terrenos a uma margem continental em geral é um processo acompanhado de intensa atividade magmática, em especial plutônica. Quando plutonismo ocorre alinhado à zona de sutura/falha, datação radiométrica direta (U-Pb em zircão magmático) pode fornecer a idade mínima do amálgama. Esta técnica é particularmente importante em terrenos pré-cambrianos, devido à escassez de conteúdo fossílifero para eventuais correlações. Exemplo clássico é o suturamento plutônico atribuído ao Pennsylvanian pluton, relacionado com o registro da colagem dos terrenos Wrangellia e Alexander, na costa oeste norteamericana (Gardner et al. 1988).

iii. Soldagem Metamórfica (Metamorphic Welding) - Em casos de metamorfismo regional pervasivo registrado em terrenos, a idade do metamorfismo pode informar a idade mínima do amálgama. A indicação de metamorfismo jurássico relacionado à colagem de terrenos da Nova Zelândia, particularmente entre os terrenos Caples e Torlesse, representa bom exemplo de soldagem metamórfica (Adams et al. 1998).

iv. Ligação de Proveniência (Provenancial Link) Quando evidências de suturamento plutônico e overlap estratigráfico não estão acessíveis ou são inexistentes, a cronologia dos eventos acrecionários pode ser inferida por variações composicionais em rochas clásticas. Um exemplo são fluxos de detritos (debris flows) com materiais de terrenos bem conhecidos depositados sobre outro terreno. Embora indireto, este critério pode fornecer boas indicações com respeito ao momento do episódio acrecionário. A análise detalhada de proveniência do Grupo Nanaimo (SW da Colúmbia Britânica, Canadá), por exemplo, determinou fontes distintas que devem ser relacionadas à colagem de terrenos. Assim, conhecidas as relações estratigráficas com terrenos, dados geocronológicos em sequências sedimentares ou metassedimentares permitem inferir o período de duração do amálgama e/ou acreção (England e Hiscott, 1992; Mustard et al., 1994, 2000).

v. Geo-história - Além dos elementos já apresentados, Howell (1995) enfatiza a importância de técnicas de análise geológica convencional, tais como observações de variações laterais de litofácies e análise estratigráfica dos possíveis candidatos a terrenos. Estudos de petrologia, por outro lado, podem sugerir evidências de atividades magmáticas distintas ou contrastantes, sejam juvenis ou fruto de retrabalhamento crustal, fornecendo, assim, forte indício de colagem. Dados estruturais podem sugerir transporte ou inversões tectônicas importantes. Qualquer evidência que indique origem distinta entre dois domínios adjacentes pode ser sugestiva de limite de terrenos.
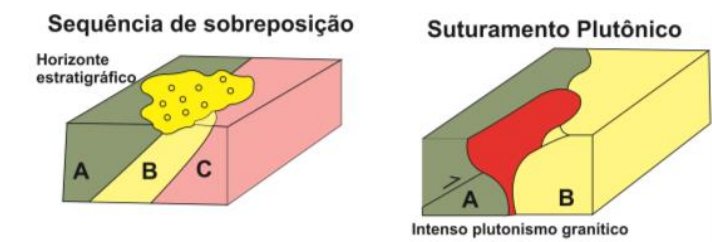

Soldagem Metamórfica

Ligação de proveniência
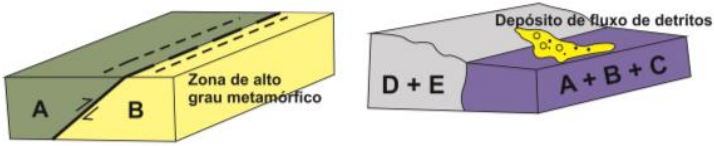

Figura 3. Diagramas esquemáticos exemplificando os resultados da amalgamação de terrenos em função do mecanismo. $A, B$ e $C$ são terrenos de natureza indefinida, enquanto $A+B+C$ e $D+E$ representam terrenos compostos. (Modificada de Howell, 1995). 


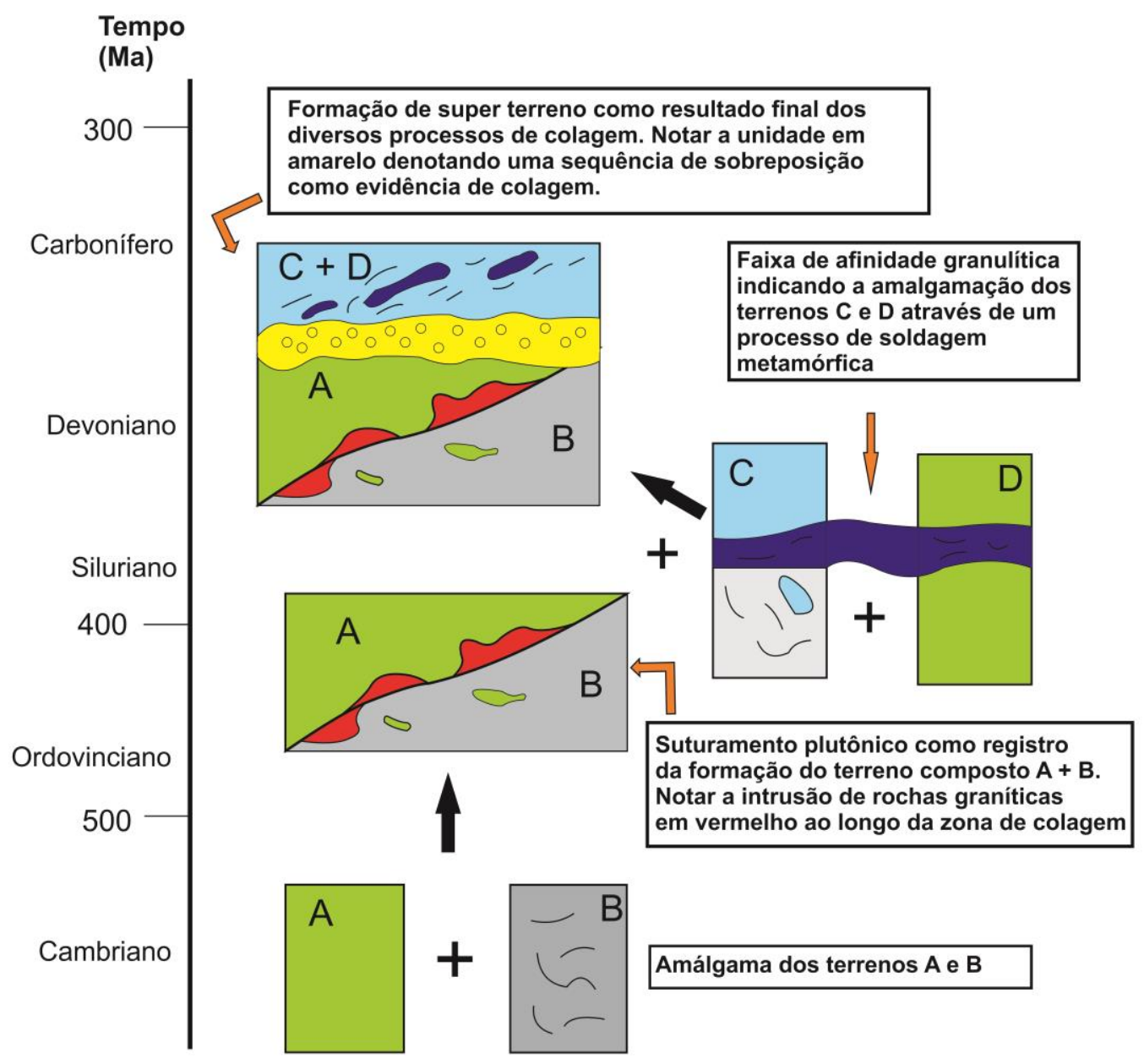

\section{LEGENDA}

Terreno Paleoproterozoico de afinidade ofiolitica

Terreno gnáissico de alto grau arqueano rico em TTGs
Terreno de afinidade continental com cobertura Neoproterozoica

Figura 4. Diagrama de assembleia tectônica (hipotético), mostrando uma sequência de colagem de terrenos de afinidades (e idades) distintas através dos diversos processos de amalgamação. Notar que os eventos não são necessariamente excludentes e podem sobrepor-se no tempo (Baseado em modelos similares apresentados por Howell, 1995).

\section{TÉCNICAS UTILIZADAS NA ANÁLISE TECTÔNICA DE TERRENOS}

A análise de terrenos corresponde a uma série de estudos, à luz da tectônica de placas, que fornecem informações a respeito da origem e dos movimentos de blocos crustais considerados potencialmente alóctones. Uma vez que um determinado terreno é identificado e tem seus limites reconhecidos, a primeira fase da análise se dá pela sua caracterização individual, seguida pelo estudo de suas relações com os terrenos adjacentes.

Análise estrutural e estratigráfica de detalhe devem ser os estudos pioneiros no processo de entendimento da origem e evolução de terrenos. 0 primeiro passo é o mapeamento geológico criterioso com o objetivo de determinar as relações entre determinado terreno e a margem continental bem como sua relação com os terrenos adjacentes (Samson et al. 1991). Dados de geofísica aérea regional podem ser particularmente importantes nesta etapa do trabalho.

Algumas técnicas específicas vêm sendo aplicadas em estudos paleogeográficos, tal como paleomagnetismo. Paleomagnetismo é o estudo do registro do campo magnético terrestre nas rochas (Butler, 1998). Neste tipo de pesquisa, as medidas de magnetismo sempre devem ser associadas à geocronologia, com objetivo de registrar o timing do magnetismo termo-remanente, obtendo-se assim, 
informações diretas sobre o campo magnético terrestre na época do resfriamento do mineral. 0 principal objetivo de estudos paleomagnéticos em análise de terrenos é determinar se alguma anomalia magnética indica a movimentação de determinado terreno em relação ao polo magnético, ou a rotação do terreno como um todo ou de blocos menores em seu interior (Howell, 1995).

Outra técnica particularmente importante na análise de terrenos é a aplicação de dados de fósseis na determinação paleogeográfica, com a utilização da chamada análise paleobiogeográfica (Haggart et al. 2006).O preceito básico é que conteúdos fossíliferos bem conhecidos determinam idades de deposição em bacias e condições paleogeográficas dos ambientes em que viveram. A distribuição geográfica dos organismos no planeta (biogeografia) é tipicamente limitada pela variação de fatores ambientais, tais como umidade, temperatura, salinidade ou ainda distribuição de nutrientes. Estudos paleobiogeográicos aplicados à análise de terrenos envolvem basicamente a comparação de distribuição espacial e temporal de fauna e flora entre os terrenos para obtenção de informações indiretas sobre os principais deslocamentos.

Embora paleomagnetismo e estudos paleontológicos sejam extremamente eficientes no entendimento de cinturões orogênicos fanerozoicos, em terrenos pré-cambrianos podem ser bastante limitados. Neste caso outras técnicas adicionais podem fornecer evidências sobre eventos acrecionários, tais como litogeoquímica e geologia isotópica.

A utilização de isótopos de $\mathrm{Nd}$ vem dando grande contribuição para a análise de terrenos mais antigos, pois permite a identificação de fontes distintas entre as unidades potencialmente alóctones e a margem continental. Esta técnica tem sido aplicada em diferentes cinturões orogênicos paleozoicos e précambrianos como, por exemplo, na separação detalhada de terrenos dos Apalaches (Wortman et al. 1996; Samson et al,. 1995). Outro bom exemplo de aplicação é apresentado por Zelek e Dickin (2013) para a região de Parent-Clova (Quebec, Canadá). Com base em mais de 100 análises correspondentes à porção central da Província Grenville, os autores separaram três regiões isotópicas distintas; uma arqueana na porção norte, uma central com idades mistas, interpretada como arco ensiálico e uma no sul, interpretada como resultado de extensão mesoproterozoica (Figura 5). A conclusão final dos autores é de que os distintos domínios isotópicos identificados representariam terrenos de origens contrastantes.

Como exemplos brasileiros, contrastes isotópicos foram identificados em blocos crustais da Faixa Ribeira, como demonstram (Dantas et al., 2000; Figura 6) e entre os terrenos Alto Moxotó e Alto Pajeú da Província Borborema (Rodrigues e Brito Neves, 2008).

Datações radiométricas, especialmente geocronologia U-Pb em zircão são indispensáveis para a identificação de fragmentos exóticos ou alóctones, seja na determinação de idades de cristalização de magmas com origens contrastantes, seja na datação de grãos detríticos de zircão, ora determinando sequências de sobreposição ou mesmo fontes distintas.

A aplicação de datações absolutas associadas com isótopos de $\mathrm{Hf}$ tem representado ferramenta robusta em estudos de proveniência e caracterização de fontes (Kinny e Maas, 2003). Exemplos de aplicações de análises isótopicas na definição de origem de terrenos são descritos em vários cinturões orogênicos ao redor do mundo, com particular destaque na identificação dos diversos períodos acrecionários dos terrenos cordilheiranos (Monger e Nokleberg, 1996; Monger e Price, 2002; Grove et al., 2008; Bermanek et al., 2012). Os principais conceitos e elementos envolvidos em análise de terrenos podem ser observados no fluxograma apresentado na Figura 7.

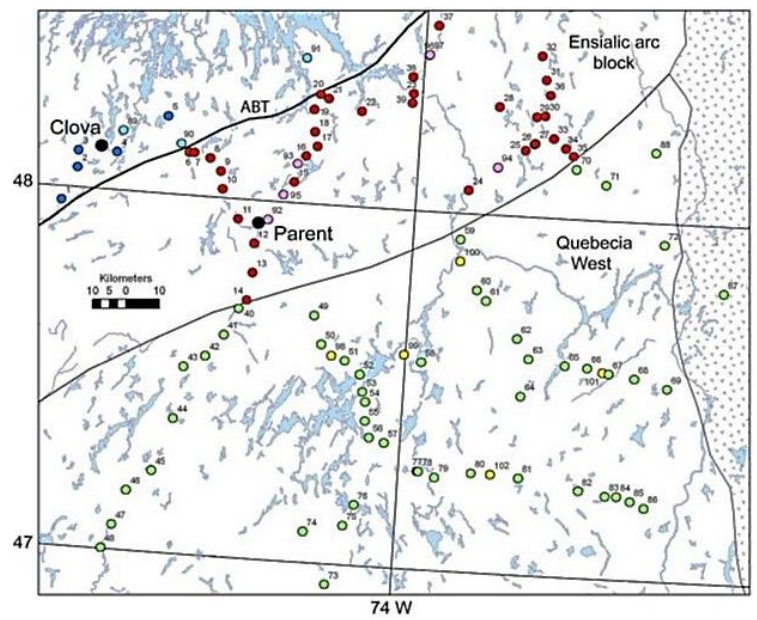

Figura 5. Distribuição geográfica das análises apresentadas por Zelek e Dickin 2013 na região de Parent-Clova (Quebec). Os círculos de cor azul escura representam rochas com idades modelo TDM mais velhas que 2,4 Ga; vermelha, amarela e azul pálido,

rochas entre 2,4 e 1,64, verde e rosa entre 1,64 e 1,37 Ga, demonstrando claramente três domínios isotópicos distintos e eficiência do método na caracterização de terrenos na Província Grenville. 


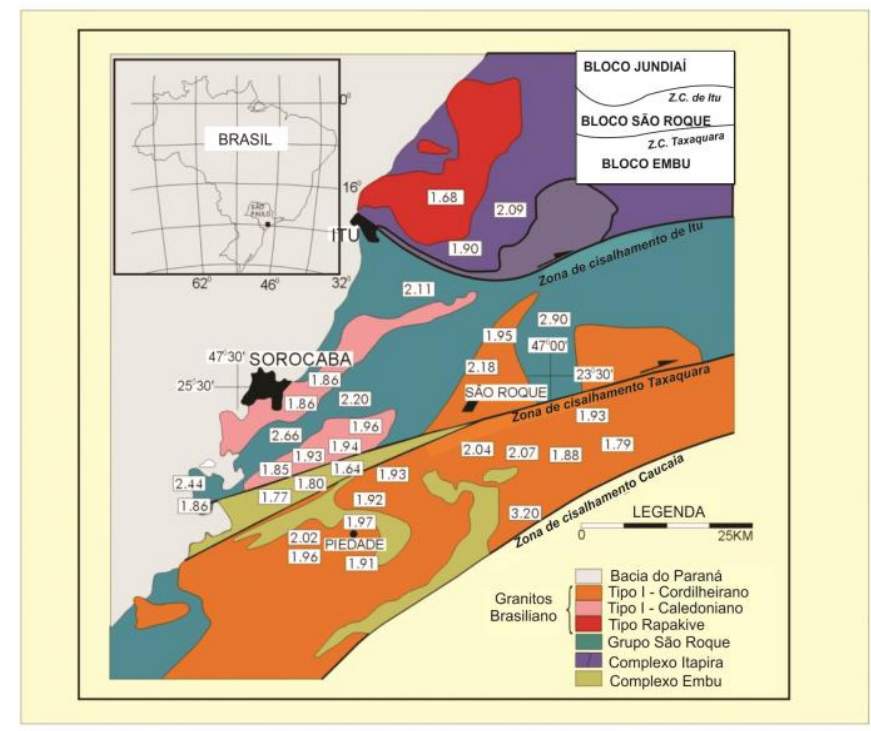

Idades Modelo TDM

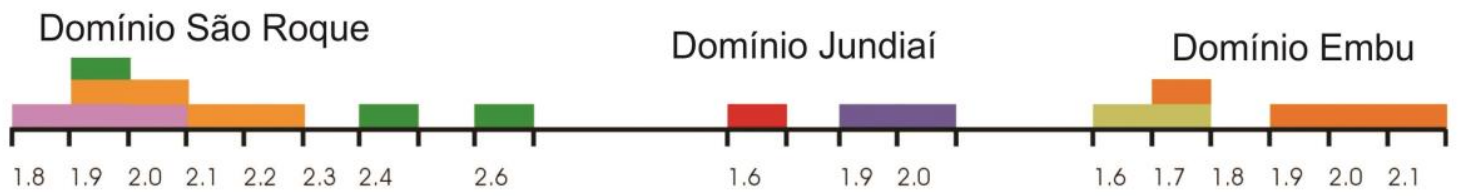

Figura 6. Distribuição de idades modelo TDM de isótopos de Nd na Faixa Ribeira no estado de São Paulo de acordo com Dantas et al., 2000. O contraste isotópico entre os distintos domínios limitados pelas falhas de Itu, Taxaquara e Caucaia pode ser interpretado como um índicio de tectônica acrescionária.

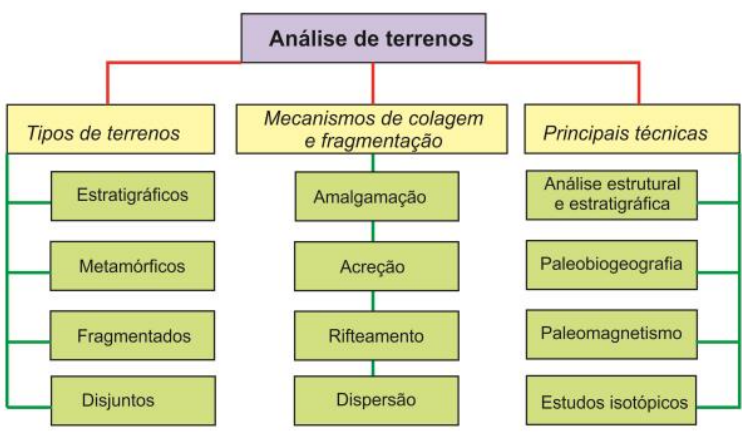

Figura 7 - Síntese dos principais elementos utilizados na análise tectônica de terrenos.

\section{REGISTRO DE TECTÔNICA ACRESCIONÁRIA EM PROVÍNCIAS NEOPROTEROZOICAS BRASILEIRAS}

\subsection{Província Tocantins (Brasil Central)}

A Província Tocantins (Almeida et al., 1981) é uma extensa área orogênica neoproterozóica resultante da convergência e colisão dos paleocontinentes Amazônico e São Francisco (Figura 8). Convergência e colisão ocorreram durante a Orogenia Brasiliana, no Neoproterozoico tardio, como parte do amálgama de Gondwana ocidental. Rochas sedimentares e vulcânicas fanerozoicas das bacias do Parnaíba, Paraná e Sanfranciscana recobrem partes da província, bem como blocos continentais estáveis mais antigos, os blocos Parnaíba e Paranapanema, ambos também envolvidos na Orogenia Brasiliana. A província compreende três faixas móveis: as faixas Araguaia e Paraguai foram formadas nas margens leste e sudeste do Cráton Amazônico, respectivamente, enquanto a Faixa Brasília ocupa as margens oeste e sul do Cráton do São Francisco.

As distintas associações petrotectônicas reconhecidas permitem a compartimentação da Faixa Brasília em zona externa e zona interna (Fuck et al., 2014 e referências ali contidas). A zona externa é constituída por cinturão de dobras-falhas composto por rochas metassedimentares de margem passiva e seu embasamento. A zona interna compreende nappes de médio e alto grau do Grupo Araxá e do Complexo Anápolis-Itauçu, o Maciço de Goiás e o Arco Magmático de Goiás, todos com vergência para o Cráton do São Francisco.

O Maciço de Goiás é constituído por terrenos granito-greenstone arqueanos e ortognaisses e sequências supracrustais paleoproterozoicas, cobertas em parte pelas rochas metassedimentares do Grupo Serra da Mesa e justapostas a leste a sequências vulcanossedimentares e complexos gabro-anortosíticos mesoproterozóicos e aos complexos máfico-ultramáficos neoproterozoicos Barro Alto, Niquelândia e Cana Brava, que formam sua borda leste.

No contexto da Faixa Brasília e da Província Tocantins e em comparação com os demais elementos tectonoestratigráficos da faixa, o Maciço 
de Goiás pode representar terreno exótico. É limitado por importantes falhas de extensão regional. A noroeste o limite é com o Arco Magmático de Goiás, determinado pela Falha Rio dos Bois, empurrão em curva com direção inicialmente próxima de E-W e mesmo NW-SE e vergência para sul, passando gradativamente para direção NE-SW e vergência sudeste. O prolongamento nordeste do empurrão adquire as características de transcorrência destra de alto ângulo, que faz parte do sistema de transcorrências do Lineamento Transbrasiliano, mais além encoberto pela Bacia do Parnaíba. O limite oeste do Maciço de Goiás é marcado pela transcorrência sinistral N-S Moiporá-Novo Brasil, que o separa da porção meridional do Arco Magmático de Goiás. $\mathrm{O}$ limite sul é constituído pela sequência paleoproterozoica Serra Dourada empurrada sobre os terrenos granito-greenstone arqueanos. 0 empurrão inflete para norte, segmentado por vários traços de falhas transcorrentes E-W, separando os terrenos arqueanos de rochas de alto grau e unidades do Grupo Araxá. Via transição pouco entendida, o limite passa para a Falha Rio Maranhão, marcando a borda do Complexo Barro Alto. A falha verga para N-NE na inflexão do

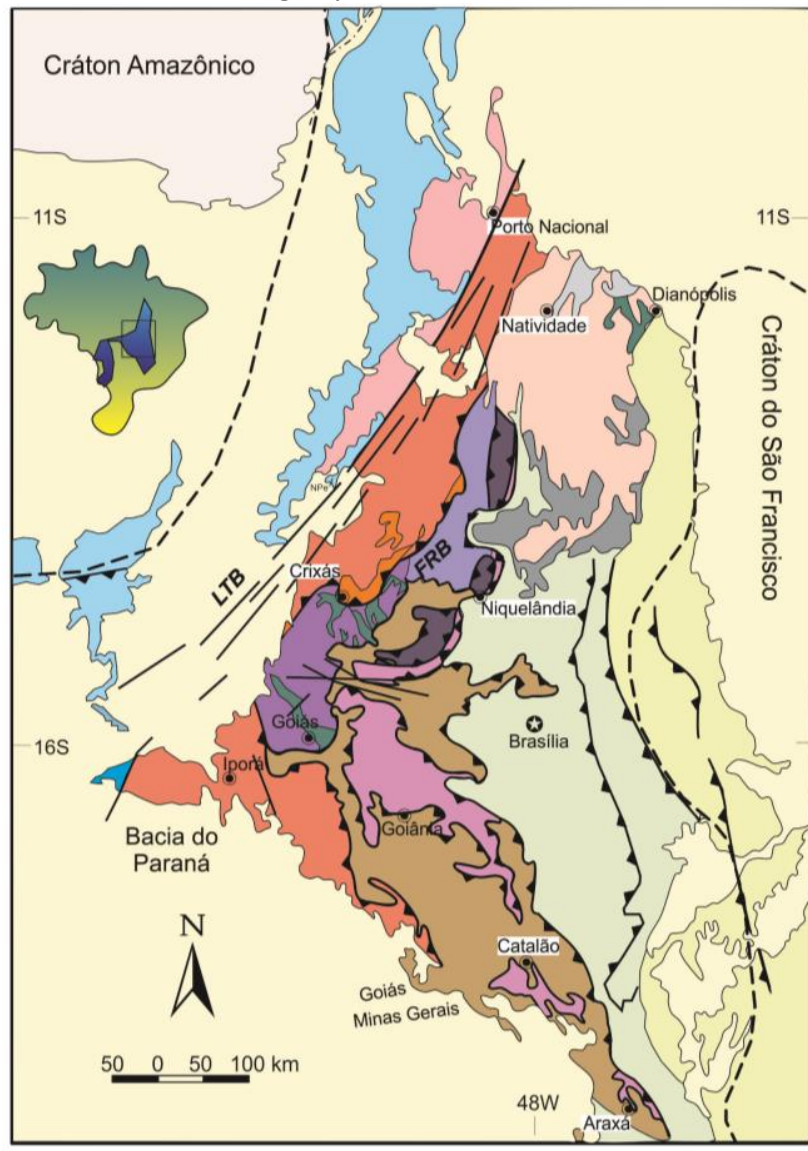

complexo, em regime de empurrão dominante, segmentado por transcorrências, sobrepondo os complexos Barro Alto, Niquelândia e Cana Brava a rochas da zona externa da faixa e seu embasamento. Em seu prolongamento NE a Falha Rio Maranhão se integra ao Lineamento Transbrasiliano, passando a transcorrência destra, adiante encoberta pela Bacia do Parnaíba.

Os dados mostram que o Maciço de Goiás é limitado por falhas em toda sua extensão e é constituído por unidades litoestratigráficas distintas em natureza, idade e evolução das rochas que o cercam. Em consequência, o Maciço de Goiás preenche as condições estipuladas pelo conceito de terrenos, podendo ser caracterizado como terreno acrescido à margem do paleocontinente São Francisco no contexto da evolução orogênica da Faixa Brasília e da Província Tocantins.

As evidências disponíveis sugerem que também o Arco Magmático de Goiás e o conjunto de rochas de alto grau metamórfico do Complexo AnápolisItauçu, limitados por extensas zonas de cisalhamento, podem ser classificados como terrenos.

\section{LEGENDA}

Cobertura Fanerozoica

\section{Faixas Paraguai e Araguaia}

Sequências supracrustais

Granulito/ortognaisse (Alto do embasamento)

\section{Faixa Brasilia}

Zona externa

$\square$ Grupo Bambui (Bacia de Foreland)

Grupos Paranoá e Canastra (Margem Passiva)

Rifte Arai $\square$ Grupo Natividade

1) Greenstone belts / Ortognaisses (Alto do embasamento)

Zona Interna

Grupo Araxá / Mélange Ofiolitica (Sutura)

Complexo Anápolis-Itauçu:

Granulitos, ortognaisses e paragnaisses (Terreno Tectonoestratigráfico)

Arco Magmático de Goiás (Terreno tectonoestratigráfico)

Sequências Vulcano-sedimentares

Ortognaisses

Maciço de Goiás (Terreno exótico?)

Cobertura dobrada / Grupo Serra da Mesa

Compl. Máfico-ultramáficos e

Sequências Vulcano-Sedimentares

Greenstone belts / Ortognaisses

Estruturas

Lineamento
Falhas ou Zonas de
Cisalalhamento de empurrão -

Figura 8 - Compartimentação tectonoestratigráfica da Província Tocantins, modificado de Fuck et al., 1994. LTB = Lineamento Transbrasiliano, FRB = Falha Rio dos Bois. 


\subsection{Província Borborema (NE do Brasil)}

A Província Borborema pode ser definida como produto da colagem neoproterozoica de um complexo sistema orogênico, que tem continuidade em várias faixas orogênicas da África ocidental (Figura 9). As cinco subprovíncias nela identificadas possuem histórias evolutivas distintas, não sendo possível definir um modelo aceitável a luz da tectônica de placas que explique toda a diversidade tectonoestratigráfica nela inserida. Isso porque, além dos mecanismos associados à colisão brasiliana, extensas zonas de cisalhamento subparalelas ao limite orógeno-cráton produziram um notável processo de dispersão, que torna problemática qualquer correlação entre os cinturões metamórficos presentes nos diferentes domínios estruturais (aqui chamados de subprovíncias) que a compõem.

As subprovíncias ao norte do Lineamento Patos possuem em comum a existência de um substrato paleoproterozoico ou arqueano-paleoproterozoico, mas o arco magmático Tamboril-Santa Quitéria e os domínios de alta/ultralta pressão de Forquilha, na subprovíncia Ceará Central, demonstram geração de crosta juvenil criogeniana e indicação de que essa porção da Província fez parte de um vasto oceano, que tem sido chamado de Goiás-Farusiano, numa reconstituição pré-deriva dos continentes africano e

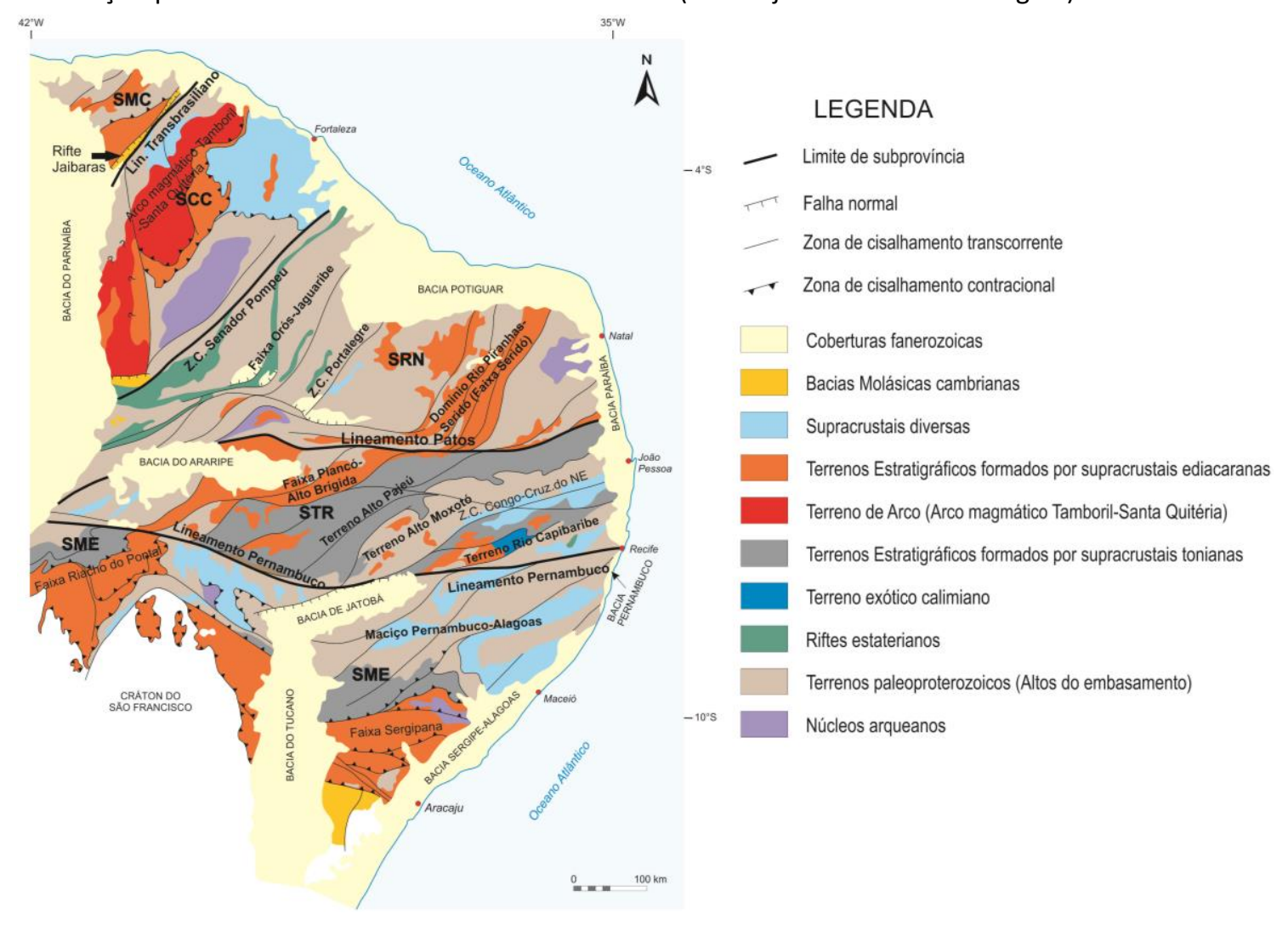

sulamericano (Cordani et al. 2013; Araújo et al. 2014). A amalgamação das duas subprovíncias é balizada pelo suturamento plutônico dos granitos Meruoca e Mucambo ao longo do Lineamento Transbrasiliano, entre 560 e 460 Ma. Sobre esse terreno composto implantou-se no final do Ediacarano e Cambriano (540-530 Ma) o rifte Jaibaras, por reativação desta importante sutura crustal, amarrando, por ligação de proveniência, a amalgamação dessas duas subprovíncias.

Entre as subprovíncias Ceará Central e Rio Grande do Norte, ocorre um terreno paleoproterozoico único na Província Borborema, o rifte estateriano Orós-Jaguaribe, que foi amalgamado aos domínios acima por soldagem metamórfica ao longo das zonas de cisalhamento Senador Pompeu e Portalegre. As subprovíncias Rio Grande do Norte e Transversal também foram soldadas metamorficamente através do Lineamento Patos, há $566 \mathrm{Ma}$. Os granitos peralcalinos de tipo Catingueira, embora de distribuição restrita, também amarram por suturamento plutônico a colagem dessas duas subprovíncias, em torno de 573 Ma. A Subprovíncia Transversal foi formada por dois episódios de colagem distintos e sucessivos: Cariris Velhos (995-920 Ma, só conhecido ao sul do Lineamento Patos) e Brasiliano (650-540 Ma), os quais geraram faixas metamórficas paralelas entre si (Alto Pajeú e Piancó-Alto Brígida).

si

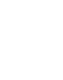


Nesse contexto, se insere o terreno paleoproterozoico, Alto Moxotó (TAM), um inlier contínuo, de grande espessura crustal, segundo confirmam recentes investigações geofísicas (Santos et al. 2014; Padilha et al. 2014; Lima et al., 2015). Apesar do intenso retrabalhamento brasiliano que afetou os blocos arqueano-paleoproterozoicos na Província, o TAM foi relativamente poupado desse processo, sugerindo uma clara aloctoneidade desse segmento crustal. A colagem do TAM ao terreno Rio Capibaribe ocorreu por soldagem metamórfica através da zona de cisalhamento Congo-Cruzeiro do Nordeste e suturamento plutônico dos granitoides peralcalinos da suíte Vila Moderna, que calibra a junção dos dois terrenos em 590 Ma.

\section{CONSIDERAÇÕES FINAIS}

i. Análise de terrenos corresponde a uma técnica multidisciplinar aplicada ao estudo de cinturões orogênicos. Envolve técnicas de geologia convencionais (mapeamento geológico, análise estrutural, paleomagnetismo, geofísica etc.) e dados laboratoriais específicos (geoquímica de rocha, isótopos etc.);

ii. O conceito de terrenos surgiu no início da década de 1980 com o objetivo de entender a origem de blocos considerados potencialmente alóctones ou suspeitos na cordilheira do oeste dos Estados Unidos, e tem sido aplicado em diversos cinturões orogênicos, tanto fanerozoicos quanto pré-cambrianos. Para aplicação do modelo de terrenos é importante que todos os elementos envolvidos no conceito sejam levados em consideração: "Pacote de rochas limitado por falhas ou zonas de cisalhamento importantes com estratigrafia e ambiente/história geológica distinta dos terrenos adjacentes". Excluem-se discordâncias ou contatos geológicos que não correspondam a falhas importantes;

iii. Terrenos ampresentam tamanhos variados, podendo ser classificados em estratigráficos, metamórficos e fragmentados, e serem descritos em função de características individuais referentes ao próprio terreno ou à margem continental. Alguns critérios são essenciais e podem auxiliar na identificação de terrenos distintos ou de limites que não são tão evidentes, tais como sequências de sobreposição, soldagem metamórfica, suturamento plutônico, ligação de proveniência, além da própria análise individual do terreno (geo-história);

iv. Platôs oceânicos podem evoluir para terrenos, sendo a evolução destes o resultado de processos de crescimento crustal (por acreção e amalgamação) e destruição e modificação crustal, como rifteamento e dispersão.
Amalgamação ocorre quando dois terrenos colidem anteriormente à acreção de material à margem continental. Dispersão representa um processo importante, pois promove o deslocamento lateral dos terrenos;

v. O modelo de colagem de terrenos tem sido reconhecido em algumas províncias estruturais neoproterozoicas brasileiras, tais como as províncias Mantiqueira, Rondoniana-San Ignácio e Sunsás. No presente trabalho são apresentados nas províncias Tocantins e Borborema elementos tectônicos sugestivos da formação e acreção de terrenos, sendo essas um bom laboratório para o teste e aplicação do modelo em cinturões orogênicos pré-cambrianos.

\section{AGRADECIMENTOS}

Este trabalho é parte integrante da pesquisa de doutorado do primeiro autor na Universidade de Brasília. Os autores expressam sinceros agradecimentos ao Prof. Miguel Tupinambá da Universidade Estadual do Rio de Janeiro e a um revisor anônimo, pela paciente leitura e precisas sugestões, as quais melhoraram substancialmente o manuscrito original. Adicionalmente, agradecemos aos editores da revista Geonomos pela atenção, paciência e auxílio em todas as etapas da publicação do artigo.

\section{REFERÊNCIAS}

Adams, C.J., Campbell H.J., Graham I.J., Mortimer N. 1998 Torlesse, Waipapa and Caples suspect terranes of New Zealand: Integrated studies of their geological history in relation to neighbouring terranes. Episodes., 21:235-240.

Almeida, F.F.M., Hasui, Y., Brito Neves, B.B., Fuck, R.A. 1981. Brazilian structural provinces: An introduction. Earth Science Reviews., 18:1-29.

Basei, M.A.S., Frimmel, H.E., Nuttman, A.P., Preciozzi, F. 2008. West Gondwana amalgamation based on detrital ages from Neoproterozoic Ribeira and Dom Feliciano belts of South America and comparision with coeval sequences from SW Africa. Journal of the Geological Society of London., 294:239256.

Ben-Avraham, Z., Nur, A., Jones, D., Cox, A., 1981. Continenta accretion: from oceanic plateaus to allochtonous terranes. Science., 213:47-54.

Bermanek, L.P., van Staal, C.R., McCelland, W.C., Israel, S., Mihalynuk, C.G. 2012. Detrital zircon $\mathrm{Hf}$ isotopic compositions indicate a northern Caledonian connection for the Alexander Terrane. Litosphere., 5:163-168.

Black R., Liégois, J.P., Latouche L., Caby R., Bertrand J.M. 1994. Pan-African displaced terranes in the Tuareg Shield (Central Sahara). Geology., 22:641-644.

Bolhar, R., Ring, U. 2001. Deformation history of the Yolla Bolly terrane at Leech Lake Mountain, Eastern belt, Franciscan subduction complex, California Coast Ranges. GSA Bulletin., 113:181-195.

Brito Neves, B.B., Santos, E.J., Schmus, W.R.V. 2000. Tectonic History of the Borborema Province. In: Umberto Cordani, 
Edson José Milani, Antonio Thomaz Filho, Diogenes de Almeida Campos. (Org). Tectonic Evolution of South America. v 1, pp. 151-182.

Brito Neves (2011). Glossário de Geotectônica. Oficina de Textos, $256 \mathrm{pp}$.

Butler, R. 1998. Palaeomagnetism: Magnetic domains to geological terranes. Blackwell Scientific Publications, Oxford, $319 \mathrm{pp}$.

Caxito, F., Uhlein, A., Stevenson, R., Uhlein, G.J. 2014. Neoproterozoic oceanic crust remmants in northeast Brazil. Geology., 42:387-390.

Coleman, R.G., Lee, E.D., Beatty, L.B., Brannock, W.W. 1965. Eclogites and eclogites: their differences and similarities. Geological Society of America Bulletin., 76:483-508.

Colpron, M., Nelson, J.L., Murphy, D.C. 2007. Northern Cordilleran terranes and their interactions trough time. GSA Today.,17:4-

Coney, P.J., Jones, D.L., Monger, J.W.H. 1980. Cordilleran suspect terranes. Nature., 288:329-333.

Cox, G.M., Lewis, C.J., Cox, A.S., Hlaverson, G.O., Jourdan, F., Foden, J., Netle, D., Kattan, F. 2012. Ediacaran terrane accretion within the Arabian-Nubian Shield. Gondwana Research., 21:341-352.

Dantas, E.L., Hackspacher, P.C., Fetter, A.H., Sato, K., Pimentel, M.M., Godoy, A.. 2000. Nd isotope systematics related to proterozoic evolution of the Ribeira Belt in the state of São Paulo, SE Brazil. Revista Brasileira de Geociências., 30:140143.

Engebretson, D.C., Kelley, K.P., Cashman, H.P., Richards, M.A. 1992. 180 million years of subduction. GSA Today., 2:93-100.

Egllington, B.M. 2006. Evolution of the Namaqua-Natal Belt, southern Africa - A geochronological and isotope geochemical review. Journal of African Earth Sciences., 46:93111.

England, T.D.J., Hiscott, R.N. 1992. Lithostratigraphy and deepwater setting of the upper Nanaimo Group (Upper Cretaceous), outer Gulf Islands of southwestern British Columbia. Canadian Journal of Earth Sciences., 29:574-595.

Faleiros, F.M., Campanha, G.A.C., Martins, L., Vlasch, S.R.F., Vasconcelos, P.M. 2011. Ediacaran high-pressure collision metamorphism and tectonics of the southern Ribeira Belt (SE Brazil): evidence for terrane accretion and dispersion during Gondwana assembly. Precambrian Research., 189:263-291.

Frey, F.A., Coffin, M.F., Wallace, P.J., Weis, D., Zhao, X., et al. 2000. Origin and evolution of a submarine large igneous province: the Kerguelen Plateau and Broken Ridge, southern Indian Ocean. Earth Planet Science Letters., 176:73-89.

Fuck, R.A., Pimentel, M.M., D’el Rey, J.H. 1994 Compartimentação tectônica na porção oriental da Província Tocantins. In: 38 Congresso Brasileiro de Geologia, v. 1. p. 215-216

Fuck, R.A., Dantas, E.L., Pimentel, M.M., Botelho, N.F., Armstrong R., Laux, J.H., Junges, S.L., Soares, E.P., Praxedes, I.F. 2014 Paleoproterozoic crust-formation and reworking events in the Tocantins Province, Central Brazil: A contribution for Atlantica supercontinent reconstruction. Precambrian Research. 244:53-74

Gardner, M.C., Bergman, S.C., Cushing, G.W., MacKevett, E.M.J., Plafker, G., Campbell, R.B., Dodds, C.J., McClelland, W.C., Mueller, P.A., 1988, Pennsylvanian pluton stitching of Wrangellia and the Alexander terrane, Wrangell Mountains, Alaska. Geology., 16:967-971.
Grobys, J.W.G., Gohl, K., Uenzelmann-Neben, G., Davy, B.W., Barker, D.H.N. 2009. Extensional and magmatic nature of the Campbell Plateau and Great South Basin from deep crustal studies. Tectonophysics., 472:213-225.

Grove, M., Gehrels, G.E., Cotkin, S., Wright, .E., Zoug, H. 2008. Non-Laurentian cratonal provenance of Late Ordovician blueschists and a link to the Alexander terrane. Geological Society of America Special Paper., 438:223-250.

Guynn, J.H., Kapp, P., Pulle, A., Gehrles, G., Ding, L. 2006. Tibetan basement rocks near Amdo reveal "missing" Mesozoic tectonism along the Bangong Suture, Central Tibet. Geology., 34:505-508.

Haggart, J.W., Enkin, R.J., Monger, W.H. 2006. Strengths and limitations of paleogeographic methods in assessing largescale displacements within the North American Cordillera. In Paleogeography of the North American Cordillera: Evidence for and against Large-Scale Displascements. Geoological Society of Canada Special Paper., 7:1-11.

Hackspacher, P.C., Dantas, E.L., Van Schmus, W.R., Fetter, A. 1997. Terrenos Exóticos na Faixa Ribeira, Sim ou não?. In: Simpósio Nacional de Estudos tectônicos. v. 1, p. 69-71.

Heilbron, M., Valeriano, C.M., Tassinari, C.C.G., Almeida, J.C.H., Tupinambá, M., Siga Jr., O., Trouw, R.A.J., 2008. Correlation of Neoproterozoic terranes between the Ribeira Belt, SE Brazil and its African counterpart: comparative tectonic evolution and open questions. In: Pankhurst, R.J., Trouw, R.A.J., Brito-Neves, B.B., de Wit, M. (Eds.), West Gondwana pre-Cenozoic Correlations Across the South Atlantic Region. Geological Society of London, Special Publication 294, pp. 211-232.

Hillhouse, J.W., Gromme, C.S., Vallier, T.L. 1982. Paleomagnetism and Mesozoic tectonics of the Seven Devils volcanic arc in northeastern Oregon: Journal of Geophysical Research., 87:3777-3794.

Howell, D.G. 1989. Tectonics of Suspect Terranes. Mountain Building and Continental Growth. Chapman \& Hall, 233 pp.

Howell, D.G. 1995. Principles of Terrane analysis. Chapman \& Hall, $245 \mathrm{pp}$.

Irving, E., Yole, R.W. 1972. Paleomagnetism and the kinematic history of mafic and ultramafic rocks in fould mountain belts. In Irving, E., Editor. The ancient oceanic lithosphere: Earh Physics Branch, Ottawa, v, 42, p. 87-95

Irwin, W.P. 1960. Geological reconnaissance of the northern Coast Ranges and Klamath Mountains, California. Div. Mines and Geology Bulletin, v. 179 80p.

Irwin, W.P. 1972. Terranes and the western Paleozoic and Triassic belt in the southern Klamath Mountains, California. In Geological Survey Research. v, 800, p. 103-111.

Jayko, A.S., Blake Jr, M.C. 1989. Deformation of the Eastern Franciscan Belt, northern California. Journal of Structural Geology., 11:375-390.

Jones, D.L., Silberling, N.J., Hillhouse, J. 1977. Wranggellia a displaced terrane in northwestern North America. Canadian Journal of Earth Sciences., 14:2565-2577.

Jones, D.L., Howell, D.G., Coney, P.J., Monger, J.W.H. 1983. Recognition character and analysis of tectono-estratigraphic terranes in western Nortth America. in Hashimoto, M., Yueda, S., eds. Accretion Tectonics in the Circum Pacific Region: Terra, v, 1 p. 21-35.

Kimbrough, D.J., Tulloch, A.J., Coombs, D.S., Landis, C.A., Johnston, M.R., Mattinson, J.L. 1994. Uranium-lead zircon ages from the Median Tectonic Zone, New Zealand. Journal of Geology and Geophisics.,37:393-419. 
Kinny, P.D., Mass, R. 2003. Lu-Hf and Sm-Nd isotope systems in zircon. Reviwes in mineralogy and geochemistry., 53:327-341.

Lima, M.V.A.G., Barrocal, J., Soares, J.E.P., Fuck, R.A. 2015. Deep seismic refraction experiment in northeast Brazil: New constraints for Borborema province evolution. Journal of South American Earth Sciences., 58:335-349.

MacKinnon, T.C. 1983. Origin of the Torlesse terrane and coeval rocks, South Island, New Zealand. Geological Society of American Bulletin., 94:967-985.

Magnani, M.B., Miller, K.C., Levander, A., Karlstron, K.E. 2004. The Yavapai-Mazatzal boundary: A long-lived tectonic element in the lithosphere of southwestern North America: Geological Society of America Bulletin., 116: 1137-1142.

Mallard, L.D., Rogers, J.J.W. 1997. Relationship of Avalonian and Caledonian terranes to Grenville and Pan-African events: Journal of Geodynamics., 23:197-221.

Monger, J.W.H., Ross, C.A. 1971. Distribution of fusulinaceans in the western Canadian Cordillera. Canadian Journal of Earth Sciences., 8:259-278.

Monger, J.W.H., Price, R.A. Tempelman-Kluit, D.J. 1982. Tectonic accretion and the origin of two metamorphic and plutonic melts in the Canadian Cordillera. Geology., 10:70-75.

Monger, J.W.H., Nokleberg., W.J. 1996. Evolution of the northern North American Cordillera: Generation, fragmentation, displacement and accretion of successive North American plate-margin arcs. in Coyner, A.R., and Fahey, P.L., eds., Geology and Ore Deposits of the American Cordillera: Geological Society of Nevada Symposium, Proceedings, v. 3, p. $1133-1152$.

Monger, J.W.H., Price, R.A. 2002. The Canadian Cordillera: Geology and tectonic evolution. Canadian Society of Exploration Geophysicists Recorder., 27:17-36.

Mortimer, N. 2004. New Zealand's geological foundations. Gondwana Research., 7:261-272.

Mustard, P.S., Rouse, G.E. 1994. Stratigraphy and evolution of Tertiari Georgia Basin and subjacent Upper Cretaceous sedimentary rocks, southwestern Britsh Columbia and northwestern Washington State. In Geological hazards of the Vancounver region, southwestern British Columbia. Geological Survey of Canada, v. 481, p. 97-170.

Mustard, P.S., Mahoney, J.B., Fanning, C.M., Friedman, R.N., McNicoll, V.J. 2000. Naraimo Group, southwest Brittish Columbia: a Late Cretaceous basin with a continuos northern provenance signature. In Cordilleran Section Annual Meeting. Geological Society of America, v. 32, p. 57.

Mustoe, G.E., Gannaway, W.L., 1997. Paleogeography and Paleontology of the Early Tertiary Chuckanut Formation, Northwest Washington. Washington Geology., 2:3-18.

Neves, S.P. 2014. Constraints from zircon geochronology on the tectonic evolution of the Borborema Province (NE Brazil): Widespread intracontinental Neoproterozoic reworking of a Paleoproterozoic Accretionary orogen. Journal of South American Earth Sciences (no prelo).

Nokleberg, W.J., Parfenov, L.M., Monger, J.W.H., Norton, I.O., Khanchuk, A.I., Stone, D.B., Scotese, C.R., Scholl, D.W., and Fujita, K., 2000, Phanerozoic tectonic evolution of the circum-North Pacific: U.S. Geological Survey Professional Paper., 1626:122 p.

Nur, A., Ben-Avraham, Z., 1982. Oceanic plateaus, the fragments of continents, and mountain building. Journal of Geophysical Research., 87:3644-3661.

Packer, D.R., Stone, D.B. 1972. An Alaskan Jurassic paleomagnetic pole and the Alaskan orocline. Nature., 237:25-26.
Padilha, A.L., Vitorello, I., Pádua, M.B., Bologna, M.S. 2014. Electromagnetic constraints for subduction zones beneath the northwest Borborema province: Evidence for Neoproterozoic island arc-continent collision in northeast Brazil, Geology., 42:91-94.

Rizzotto, G.J., Quadros, M.L., 2005. Geologia do Sudoeste do Cráton Amazônico. In: Horbe, Adriana; Souza, Valmir da Silva (Orgs.). Contribuições à Geologia da Amazônia. 69-84.

Ramos, V.A., Dallmeyer, R.D., Vujovich, G.L. 1998. Time constraints on the early Paleozoic docking of the Precordillera, central Argentina, in Pankhurst, R.J., Rapela, C.W., Eds. The proto-Andean margino of Gondwana: The Geological Society of London Special Publication., 142:143158.

Rodrigues, S.W.O., Brito Neves, B.B. 2008. Padrões isotópicos Sm$\mathrm{Nd}$ no limite entre os Terrenos Alto Pajeú e Alto Moxotó (PB). Revista Brasileira de Geociências., 38:211-227.

Samson, S.D., Hibbard, J.P., Wortman, G.L. 1995. Nd isotopic evidence for juvenile crust in the Carolina terrane, southern Appalachians: Contributions to Mineralogy and Petrology., 121:171-184.

Santos, A.C.L., Padilha, A.L., Fuck, R.A., Pires, A.C.B., Vitorello, I., Pádua, M.B. 2014. Deep structure of a stretched lithosphere: Magnetotelluric imagin of the southeastern Borborema Province, NE Brazil. Tecthonophysics., 610:39-50.

Santos, E.J. 1996. Ensaio preliminar sobre terrenos e tectônica acrescionária na Província Borborema. In 39o Congresso Brasileiro de Geologia, v 1, pp. 47-50.

Santos, E.J. ; Souza Neto, J.A. ; Silva, M.R.R. ; Beurlen, H. ; Cavalcanti, J.A.D. ; Silva, M.G. ; Dias, V.M. ; Costa, A.F. ; Santos, L.C.M.L. ; Santos, R.B. Metalogênese das porções norte e central da Província Borborema. In: Maria da Glória da Silva; Manoel Barreto da Rocha Neto; Hardy Jost; Raul Minas Kuyumjian. (Org.). 2014. v. 1. p. 343-388.

Scandolara, J., Amorim, J.L., Rizzoto, G.J., Quadros, M.L.E.S., 2001. Evolução geológica do segmento sudoeste do Cráton Amazônico Estado de Rondônia e adjacências.. In: Nélson Reis; Marcos Monteiro. (Org.). Contribuições à Geologia da Amazônia. Manaus: SBG/Núcleo Norte, v. 2, p. 251-340.

Schermer, E., Howell, D.G., Jones, D.L. 1984. The origin of allochtonous terranes: perspectives on the growth and shaping of continents. Annual Reviews of Earth and Planetary Sciences., 12:107-131.

Schubert, G., Sandwell, D. 1989. Crustal volume of the continents and of oceanic and continental submarine plateaus. Earth and Planetary Letters., 92:234-246.

Stoeser, D.B., Frost, C.D. 2006. $\mathrm{Nd}, \mathrm{Pb}, \mathrm{Sr}$ and $\mathrm{O}$ isotopic characterization of Saudi Arabian Shield Terranes. Chemical Geology., 226: 163-188.

Van Schmus, W.R., Oliveira, E.P., Silva Filho, A.F., Toteu, F., Penaye, J., Guimarães, I.P. 2008. Proterozoic links between the Borborema Province, NE Brazil, and the Central African Fold Belts. Geological Society of London, Special Publications., 294:66-69.

Vogt, K., Gerya, T.V. 2012. From oceanic plateaus to allochtonous terranes: Numerical modelling. Gondwana Research., 25:494508.

Wortman, G., Samson, S.D., Hibbard, J.P. 1996. Discrimination of the Milton and Carolina slate belts, southern Appalachians: A Nd isotopic approach. Journal of Geology;. 104:249-247.

Zegers, E.T., van Keken, P.E. 2001. Middle Archean continent formation by crustal delamination. Geology., 29:1038-1086.

Zelek, M., Dickin, A. 2013. Nd isotope mapping of crustal terranes in the Parent-Clova Area, Quebec: Implications for the evolution of Laurentian Margin in the Centra Grenville Province. Geosciences., 3:448-465 